\title{
Consideraciones generales sobre los límites del control judicial del debido proceso en los pro- cedimientos desarrollados ante las comisiones investigadoras del Congreso de la República General concerns on the judicial supervision limits of the due process in the procedures before the inquiry commis- sions in the Congress
}

\author{
CÉSAR LANDA ARROYO*
}

Resumen: Durante los últimos años se observa una paulatina intervención del Poder Judicial en las competencias y atribuciones del Parlamento para fiscalizar o investigar asuntos de interés público, llegando a cuestionarse el propio principio de separación de poderes. En dicho contexto, el presente artículo busca analizar cuáles son los límites del control judicial del debido proceso sobre los procedimientos que se desarrollan a través de las comisiones de investigación del Congreso de la República.

Palabras clave: debido proceso - procedimientos parlamentarios - control judicial - separación de poderes - justicia constitucional

\begin{abstract}
In the last years, there is a gradually participation of the Judicial Branch in the Congress competences and functions to supervise and inquire into issues of public interest. As a result, it has questioned the separation of powers principle. In that context, this article focuses on analyzing what the judicial supervision limits of the due process in the procedures before the inquiry commissions in the Congress are.
\end{abstract}

Key words: due process, parliamentary procedures, judicial supervision, separation of powers, constitutional justice

CONTENIDO: I. INTRODUCCIÓN.- II. EL DEBIDO PROCESO EN LOS PROCEDIMIENTOS PARLAMENTARIOS: JURISPRUDENCIA INTERAMERICANA Y JURISPRUDENCIA CONSTITUCIONAL PERUANA.- II.1. JURISPRUDENCIA DE LA CORTE INTERAMERICANA DE DERECHOS HUMANOS SOBRE EL JUICIO POLÍTICO ANTE EL CONGRESO.- II.2. JURISPRUDENCIA DEL TRIBUNAL CONSTITUCIONAL PERUANO SOBRE EL ANTEJUICIO POLÍTICO SEGUIDO ANTE EL CONGRESO.- III. CASOS DE TENSIÓN SOBRE EL EJERCICIO DE LAS FACULTADES INVESTIGADORAS DEL PARLAMENTO Y SU CONTROL POR LA JUSTICIA CONSTITUCIONAL PERUANA.- III.1. CASO ALAN GARCÍA PÉREZ.- III.2. CASO ALEJANDRO TOLEDO MANRIQUE.- IV. UN CASO

* Profesor principal del Departamento de Derecho de la Pontificia Universidad Católica del Perú. Expresidente del Tribunal Constitucional del Perú. Correo electrónico: clanda@pucp.edu.pe 
PARADIGMÁTICO: CONTROL JUDICIAL DE LA SANCIÓN IMPUESTA AL CONGRESISTA JAVIER DIEZ CANSECO.- V. LIIMITES AL CONTROL JUDICIAL DEL RESPETO AL DEBIDO PROCESO EN LOS PROCEDIMIENTOS ANTE LAS COMISIONES INVESTIGADORAS DEL PARLAMENTO.- VI. CANON DE CONTROL CONSTITUCIONAL DEL DEBIDO PROCESO.- VI.1. DEBIDO PROCESO: ENTRE REGLAS Y PRINCIPIOS.- VI.2. CONTENIDO DEL DEBIDO PROCESO EXIGIBLE EN LOS PROCEDIMIENTOS DE INVESTIGACIÓN PARLAMENTARIA.- VI.3. INTENSIDAD DEL CONTROL DEL DEBIDO PROCESO EN SEDE PARLAMENTARIA DE INVESTIGACIÓN: DEL CONTROL DÉBIL AL CONTROL ESTRICTO.- VII. REFLEXIONES FINALES: ¿JUDICIALIZACIÓN DE LA POLÍTICA O POLITIZACIÓN DE LA JUSTICIA?

\section{INTRODUCCIÓN}

Considerando que en toda democracia constitucional se presenta una permanente tensión entre las mayorías y las minorías representadas en el Parlamento y entre el gobierno y la oposición, no es ajeno a dichos conflictos políticos que los mismos desborden la capacidad de resolución dentro del propio del Parlamento y terminen resolviéndose o ventilándose en sede judicial. En dicho contexto, en el Perú en los últimos años, dados los diversos procedimientos de investigación parlamentaria desarrollados ${ }^{1}$, sobre todo contra expresidentes, se observa una paulatina intervención del Poder Judicial en las competencias y atribuciones del Parlamento para fiscalizar o investigar asuntos de interés público, según el artículo 97 de la Constitución ${ }^{2}$. Lo cual llega a poner en cuestión el propio principio de separación de poderes, incluso en su variante contemporánea del control y balance de poderes.

Así, a modode ejemplo, el expresidente Alan García, actualmente inmerso en una investigación parlamentaria por algunos actos de corrupción suscitados durante su mandato constitucional, como el otorgamiento de 5246 gracias presidenciales (de las cuales 400 fueron por narcotráfico), interpuso una demanda de amparo contra la Comisión Investigadora. Esta, mejor conocida como la «Megacomisión», fue constituida por el pleno del Congreso con 110 votos en el año 2011 para investigar dichos hechos entre otros. En dicho proceso judicial, la demanda fue declarada

1 La investigación parlamentaria vía comisiones especiales es una típica expresión de la función de control político que incumbe al Parlamento. Por ello, César Delgado-Guembes afirma que «el propósito de una comisión investigadora es indagar sobre asuntos públicos, o de efectos públicos, que afectan el regular manejo de la hacienda o fondos públicos o el incumplimiento de la Constitución o las leyes" (DELGADo-GuemBes, César. Manual del Parlamento. Introducción al estudio del Congreso peruano. Lima: Congreso de la República, Oficialía Mayor, 2012, p. 457).

2 Artículo 97. Función Fiscalizadora: «El Congreso puede iniciar investigaciones sobre cualquier asunto de interés público. Es obligatorio comparecer, por requerimiento, ante las comisiones encargadas de tales investigaciones, bajo los mismos apremios que se observan en el procedimiento judicial. Para el cumplimiento de sus fines, dichas comisiones pueden acceder a cualquier información, la cual puede implicar el levantamiento del secreto bancario y el de la reserva tributaria; excepto la información que afecte la intimidad personal. Sus conclusiones no obligan a los órganos jurisdiccionales». 
fundada, al determinarse que se le vulneró el derecho a la comunicación previa y detallada de los cargos por las cuáles se le investiga, contenido del derecho a un debido proceso parlamentario. Asimismo, se dispuso la nulidad de una serie de actuaciones parlamentarias desarrolladas por la Megacomisión, incluidas las propias declaraciones brindadas por García a la citada comisión.

Por ello, resulta relevante preguntarnos, icuáles son los límites del control que puede ejercer la justicia constitucional sobre los procedimientos que se desarrollan mediante las comisiones de investigación del Parlamento cuando se trate de proteger los derechos contenidos en el debido proceso parlamentario? Como se sabe, el inciso 3 del artículo 139 de la Constitución peruana reconoce el derecho al debido proceso como un principio y derecho de la función jurisdiccional. No obstante, es amplia la jurisprudencia del Tribunal Constitucional que reconoce que su aplicación no se limita al proceso judicial, sino que es aplicable y exigible su respeto tanto en los procedimientos que se desarrollan ante la administración pública ${ }^{3}$, como en los procedimientos corporativoparticulares ${ }^{4}$.

Así, no es sorpresivo que se exija el respeto del debido proceso ante los procedimientos que despliega el Congreso de la República, pero solo con relación a procedimientos como el antejuicio político contra determinadas autoridades, que pueden ser imputadas de una infracción constitucional o delito en ejercicio de sus funciones, o el juicio político contra dichas autoridades, el cual puede terminar destituyéndolas, suspendiéndolas o inhabilitándolas para cargos públicos. Sin embargo, dado que las comisiones investigadoras no acusan ni sancionan, la exigencia judicial del cumplimiento del debido proceso, como en los casos anteriores, no tendría una base argumentativa constitucional ni fundamento jurídico consistente.

3 Entre otras tantas, ver la sentencia del expediente 2050-2002-AA, fundamento 12, en donde se tiene expuesto que: "es doctrina consolidada de este Colegiado que el derecho reconocido en el inciso 3) del artículo 139 de la Constitución no solo tiene una dimensión, por así decirlo, "judicial", sino que se extiende también a sede "administrativa" y, en general, como la Corte Interamericana de Derechos Humanos lo ha sostenido, a "cualquier órgano del Estado que ejerza funciones de carácter materialmente jurisdiccional, (la que) tiene la obligación de adoptar resoluciones apegadas a las garantías del debido proceso legal, en los términos del artículo 8 de la Convención Americana". (Caso Tribunal Constitucional del Perú, párrafo 71)». En el mismo sentido, puede verse el fundamento 23 de la sentencia del expediente 0090-2004-AA.

4 En la sentencia del expediente 1612-2003-AA, fundamento 5, el Tribunal Constitucional dejó establecido que: «si bien el Estatuto de la Asociación no ha establecido un procedimiento disciplinario sancionador, sin embargo, para el Tribunal Constitucional queda claro que el debido proceso -y los derechos que lo conforman, p.e. el derecho de defensa - rigen la actividad institucional de cualquier persona jurídica, máxime si ha previsto la posibilidad de imponer una sanción tan grave como la expulsión -inciso c) del artículo 20 del Estatuto-, razón por la cual los emplazados, si consideraron que el actor cometió alguna falta, debieron comunicarle por escrito los cargos imputados, acompañando el correspondiente sustento probatorio, y otorgarle un plazo prudencial a efectos de que -mediante la expresión de los descargos correspondientes- pueda ejercer cabalmente su legítimo derecho de defensa". En sentido similar pueden verse la sentencia del expediente 14612004-AA, fundamento 3 , y la sentencia del expediente 5314-2007-AA, fundamento 5 . 
Esta hipótesis incluso tiene sustento en la jurisprudencia de la Corte Interamericana de Derechos Humanos. Esto no es óbice para reconocer que resulta necesaria la aplicación del debido proceso al ámbito de los procedimientos desarrollados por las comisiones investigadoras del Parlamento, pero de forma mínima o en lo esencial, ya que dicha tarea parlamentaria no es un proceso sancionador y menos un proceso judicial $^{5}$.

A continuación, vamos a describir la tesis jurisprudencial mayoritaria, representada por las sentencias de la Corte Interamericana de Derechos Humanos y del Tribunal Constitucional peruano. Seguidamente, vamos a describir los casos más relevantes que a la fecha se han presentado en el escenario peruano sobre el control judicial de los procedimientos parlamentarios de investigación sobre asuntos de interés público. Luego, se realizará una aproximación a nuestra propuesta, consistente en la aplicación por niveles o intensidades del debido proceso en el seno de los procedimientos desarrollados por las comisiones de investigación del Congreso de la República. Finalmente, concluiremos con algunas reflexiones sobre la tensión que puede surgir entre la justicia constitucional y el Parlamento por el control jurisdiccional del debido proceso parlamentario vinculado a las comisiones investigadoras en sede de la justicia constitucional.

\section{EL DEBIDO PROCESO EN LOS PROCEDIMIENTOS PARLAMENTARIOS:JURISPRUDENCIAINTERAMERICANA Y JURISPRUDENCIA CONSTITUCIONAL PERUANA \\ II.1. Jurisprudencia de la Corte Interamericana de Derechos Humanos sobre el juicio político ante el Congreso}

La Corte Interamericana de Derechos Humanos (Corte IDH) ha tenido oportunidad de analizar la aplicación del debido proceso parlamentario con ocasión del caso «Tribunal Constitucional vs. Perú» ${ }^{6}$. En este caso, resuelto en el año 2001, los magistrados del Tribunal Constitucional (TC), destituidos durante el régimen autocrático de Fujimori (1990-2000) por oponerse a la ley de reelección presidencial, Delia Revoredo Marsano, Guillermo Rey Terry

5 Tal es el caso del modelo español, donde las facultades de las comisiones de investigación parlamentarias no se asimilan a las del Poder Judicial. Al respecto, ver TORRES BONET, María. "Las relaciones entre las comisiones de investigación y el Poder Judicial». En Congreso de los Diputados. VI Jornadas de Derecho Parlamentario. Problemas actuales del Control Parlamentario, 25 de enero de 1995. Madrid: Publicaciones del Congreso de los Diputados, 1997, pp. 662-663.

6 Corte Interamericana de Derechos Humanos. "Caso del Tribunal Constitucional contra Perú». Sentencia del 31 de enero de 2001. Para mayores alcances y reflexiones sobre este caso puede verse Paniagua CoRAZAO, Valentín. Constitución, democracia y autocracia. México: UNAM, 2004, pp. 109-163. 
y Manuel Aguirre Roca, fueron víctimas de una persecución política que inició con un procedimiento de investigación ante una Comisión. La finalidad de esta última fue investigar la sustracción de documentos de la oficina de la magistrada Revoredo Marsano. La Comisión encargada del procedimiento, antes que pronunciarse sobre el objeto de su investigación, arbitrariamente concluyó que debía abrirse juicio político contra los magistrados Revoredo Marsano, Rey Terry y Aguirre Roca, debido a que dichos magistrados, que habían votado por la inconstitucionalidad de la ley de la re-reelección del entonces presidente Fujimori y habían hecho sentencia, habían resuelto un recurso de aclaración en nombre del Pleno, el mismo que había sido solicitado por el presidente del TC. La arbitrariedad de la mayoría parlamentaria se procesó mediante un juicio político que terminó con la destitución de dichos magistrados?

Cuando la Corte IDH analizó el fondo de las violaciones alegadas, sostuvo que el respeto de las garantías judiciales no se limitaba al ámbito judicial en estricto, sino que son requisitos que deben observarse en todas las instancias procesales, a efectos de que las personas puedan defenderse frente a cualquier acto emanado del Estado (fundamento 69). Respecto al sometimiento de las personas a un juicio político, ejercido por el Parlamento y que derivaría en una serie de responsabilidades para el funcionario enjuiciado, la Corte recordó lo siguiente. Toda persona sometida a cualquier tipo de juicio ante un órgano estatal que ejerza funciones materialmente jurisdiccionales (fundamento 71) debe contar con la garantía de que dicho órgano sea competente, independiente e imparcial y actúe en los términos del procedimiento legalmente previsto para el conocimiento y la resolución del caso al que se le somete (fundamento 77).

Luego de ello, la Corte dio cuenta de las lesiones a los derechos componentes del debido proceso de los magistrados destituidos: la Comisión sustituyó el objeto de su investigación sin comunicación previa a los magistrados, quienes de denunciantes pasaron a ser denunciados en un juicio político; por lo que no se les comunicó previa y detalladamente de los cargos en su contra; el plazo para poder ejercer su defensa fue extremadamente corto; se les impidió el acceso a las pruebas pertinentes para poder elaborar su defensa; a los magistrados acusados no se les permitió contra interrogar a los testigos. Por ello, dicho procedimiento no aseguró las garantías mínimas que conforman el debido proceso (fundamentos 80-85).

7 Ver «Acusación de los congresistas Enrique Chirinos Soto y Luis Delgado Aparicio, miembros de la Comisión acusadora contra cuatro magistrados del Tribunal Constitucional y los alegatos presentados por los doctores Valentín Paniagua, Raúl Ferrero, Juan Monroy y Manuel Aguirre, en defensa de los miembros del Tribunal Constitucional, en la sesión plenaria del 28 de mayo de 1997». Pensamiento Constitucional, IV, 4 (1997), pp. 421-504. 
Si bien coincidimos con la línea expuesta por la Corte IDH, no podemos dejar de mencionar que la exigencia mínima del debido proceso que la Corte exige está referido a un caso de un juicio político, antes que a la labor de una comisión investigadora, por ello, exige el respeto de grados mínimos del debido proceso, más aún si al no respetar el debido proceso mínimo, se afecta el derecho a la independencia del juez, establecida en el artículo 25 de la Convención Americana de Derechos Humanos. En consecuencia, si entendemos adecuadamente la sentencia, la Corte IDH no exige una aplicación intensa del debido proceso, al punto que se equipare un juicio político con un proceso judicial.

Más aún, en el caso de Barreto y Leiva contra Venezuela ${ }^{8}$, la Corte IDH aseguró un control estricto y expansivo del derecho a la comunicación previa y detallada de la acusación, sobre la base del artículo 8.2 de la Convención Americana de Derechos Humanos, pero frente a hechos punibles. Esto es, el Estado debe informar al interesado no solamente de la causa de la actuación, es decir las acciones u omisiones que se imputan, sino también las razones que llevan al Estado a formular la imputación, los fundamentos probatorios y la caracterización legal que se da a los hechos.

Así lo señala la Corte, debido a que el derecho de defensa debe poder ejercerse desde que se señala a una persona como posible autor o partícipe de un hecho punible y solo culmina cuando termina el proceso. De modo que la importancia de definir previamente la calidad de la persona citada para emitir su declaración informativa o la calidad de investigado para rendir su declaración indagatoria es fundamental para el derecho de defensa; pero, como ha señalado la Corte IDH esto es válido en un proceso judicial penal. La exigencia no resulta razonable ni proporcional en procesos que no son sancionadores y menos aún en procesos de parlamentarios de investigación sobre asuntos de interés público.

\section{II.2. Jurisprudencia del Tribunal Constitucional peruano sobre el antejuicio político seguido ante el Congreso}

El 8 de agosto de 2012, el TC emitió sentencia, recaída en el expediente 00156-2012-PHC, y rechazó la demanda de hábeas corpus que solicitaba la invalidez absoluta del procedimiento parlamentario de antejuicio político, por la supuesta vulneración de los derechos constitucionales al debido proceso del exmagistrado del Poder Judicial César Humberto Tineo Cabrera. En la controversia se cuestionaba el antejuicio seguido

8 Corte Interamericana de Derechos Humanos. «Caso Barreta Leiva contra Venezuela». Sentencia del 17 de noviembre de 2009, Fundamentos 26-36. 
por el Congreso de la República, al finalizar el régimen de Fujimori, a un grupo de magistrados que colaboraron con el régimen de facto. Por ello, el Congreso declaró haber lugar al inicio de causa penal contra ellos. En la prosecución del proceso penal, el exmagistrado César Humberto Tineo Cabrera interpuso demanda de hábeas corpus contra la validez del procedimiento parlamentario de antejuicio.

En la sentencia del TC se despliega un conjunto de consideraciones sobre el derecho al debido proceso: legalidad y taxatividad de las sanciones aplicables, comunicación previa y detallada de la acusación, tiempo y medios para la defensa, principio non bis in idem, plazo razonable, entre otros, como si se tratara de un proceso penal. Asimismo, desarrolla y contextualiza estas manifestaciones del debido proceso en el procedimiento político parlamentario, ocupándose extra petita no solo del antejuicio, sino también del juicio político y de la labor de las Comisiones Investigadoras del Congreso. En esta sentencia, el TC utiliza arbitrariamente como herramienta de argumentación la abundante jurisprudencia internacional sobre el debido proceso en sede judicial, tanto de la Corte Interamericana como del Tribunal Europeo de Derechos Humanos.

De los argumentos expuestos en la sentencia, se aprecia la formulación de un canon estricto sobre el control del debido proceso en los procedimientos parlamentarios, sin hacer las necesarias modulaciones que dicho canon puede incluir. $\mathrm{Al}$ respecto, en el fundamento 4 de la sentencia citada se afirmó lo siguiente:

En sede parlamentaria, este derecho debe ser respetado no solo en los procedimientos de antejuicio y de juicio político, sino también en las actuaciones de las Comisiones Investigadoras o de las Comisiones Ordinarias que reciben el encargo expreso del Pleno del Congreso de la República; y merece una tutela reforzada, en tanto que el Congreso de la República decide por mayoría y actúa por criterios basados en la oportunidad y conveniencia, es decir, que su actuación y canon de control es de carácter subjetivo porque no ejerce función jurisdiccional propiamente dicha.

Sin embargo, de la lectura de la misma no se aprecia por qué razón, en el ámbito de las comisiones investigadoras del Parlamento, el control judicial del debido proceso «merece una tutela reforzada». Si bien se alude a los criterios de «oportunidad o conveniencia», ellos atañen directamente al momento o razones de su constitución, pero luego de ello, la actuación de las comisiones se ciñe, en el marco de su mandato, a las reglas establecidas en el artículo 88 del Reglamento del Congreso de la República. Más aún si, como la misma sentencia del TC expone, la Corte IDH exige la aplicación y control del debido proceso en aquellas 
instancias que ejerzan funciones materialmente jurisdiccionales (como lo son, a propósito de los procedimientos parlamentarios, el juicio político y el antejuicio), no hay coherencia lógica en extender dicho parámetro estricto de control judicial a la comisiones investigadoras, si las conclusiones que se contienen en el informe final de estas comisiones no revisten un carácter sancionador.

Ello es así en tanto y en cuanto las mismas no vinculan ni al Ministerio Público para formular denuncia penal, ni al Poder Judicial para abrir investigación judicial, según lo establecido en el mismo artículo 97 in fine de la Constitución'. Por ello, las conclusiones de los informes finales no pueden variar la situación jurídica de la o las personas vinculadas con las investigaciones.

De otro lado, no debe perderse de vista, que la aplicación estricta del debido proceso conlleva la equiparación de los procedimientos parlamentarios con un proceso judicial. Ello acarrea que la justicia constitucional de primera instancia pueda invadir fueros de otro poder del Estado. Claro, esta apreciación no significa que se deje a los ciudadanos sin ningún tipo de protección, menos aún, postular la no aplicación del debido proceso en sede parlamentaria. Postulamos, sí, una aplicación constitucionalmente adecuada, necesaria y proporcional del debido proceso al interior de los procedimientos desarrollados por las comisiones investigadoras.

De esta manera, la conformación de una comisión investigadora será un medio adecuado en tanto su finalidad consista en esclarecer hechos de relevancia pública. Su trabajo será necesario en tanto los medios empleados durante las indagaciones de la comisión, previstos en el artículo 88 del Reglamento del Congreso, sean razonables y estrictamente necesarios para lograr el esclarecimiento de los hechos materia de investigación. Finalmente, deberá ponderarse los resultados de la misma, a fin de determinar si el trabajo de la comisión logró o no el cometido para el cual se conformó. Asimismo, no debe olvidarse que tanto la facultad de constituir una comisión investigadora y que la misma logre su cometido como el respeto del debido proceso son fines constitucionalmente relevantes. Ello es así en tanto el artículo 97 de la Constitución establece que el Congreso puede iniciar investigaciones sobre cualquier asunto de interés público y sus conclusiones, a las que se arriba luego de las indagaciones, no obligan a los órganos jurisdiccionales. Asimismo, el artículo 139 garantiza una serie de derechos vinculados al debido proceso. Dichos fines, en el marco del control judicial, deberán ser concordados por las instancias judiciales de modo tal que se pueda

9 Artículo 97 de la Constitución: «El Congreso puede iniciar investigaciones sobre cualquier asunto de interés público. [...] Sus conclusiones no obligan a los órganos jurisdiccionales». 
lograr compatibilizar el ejercicio de las prerrogativas parlamentarias con el respeto del debido proceso en el desarrollo de las actuaciones de las comisiones investigadoras.

\section{III.CASOS DE TENSIÓN SOBRE EL EJERCICIO DE LAS FACULTADES INVESTIGADORAS DEL PARLAMENTO Y SU CONTROL POR LA JUSTICIA CONSTITUCIONAL PERUANA}

Los procesos constitucionales iniciados por los expresidentes García y Toledo contra las comisiones investigadoras conformadas por el Pleno del Congreso están vinculados al objeto del presente artículo. En el primer caso, se ha tenido como finalidad investigar hechos de relevancia pública vinculados con actos de gestión que tuvieron lugar durante el gobierno de García (dación de gracias presidenciales a cientos de condenados por narcotráfico, irregularidades en el programa «Agua para Todos» y en la construcción de los denominados «colegios emblemáticos»). En relación con el segundo caso, se ha investigado la participación del expresidente Toledo en la constitución y operaciones de una empresa, ECOTEVA, para la adquisición de inmuebles a su favor, cuyo patrimonio resulta difícil justificar.

\section{III.1. Caso Alan García Pérez}

$\mathrm{Al}$ inicio del presente período gubernamental, el Pleno del Congreso de la República constituyó una Comisión Investigadora a cargo de investigar presuntos actos de corrupción ocurridos en el gobierno del expresidente Alan García Pérez. Dicha investigación ha sido cuestionada por el expresidente ante el Poder Judicial. En su demanda de amparo se invoca la afectación, por parte de la Comisión Investigadora, de los derechos a no ser desviado del procedimiento preestablecido, la comunicación previa y detallada de los hechos que se imputan, el derecho a la defensa, y el derecho al «juez parlamentario» imparcial.

Como fundamentos de su demanda, Alan García señala que la Comisión propaló un informe preliminar en el que, no obstante no haber asistido aún a brindar su declaración ante la Comisión, se lo involucraba en el caso de las denominadas gracias presidenciales a favor de sentenciados por narcotráfico. Asimismo, cuestionaba el hecho de que la Comisión utilice un denominado «Reglamento de la Comisión» que no ha sido publicado, con lo que se le desviaba de los procedimientos preestablecidos. También alegó que, a pesar de solicitar un informe del Ministerio de Justicia sobre más de 400 conmutaciones de pena a favor de sentenciados por tráfico ilícito de drogas, la Comisión solo le alcanzó una lista con una serie de nombres, sin firma o sello alguno que le otorgue validez y sin ninguna indicación sobre la naturaleza de la irregularidad.

CONSIDERACIONES GENERALES SOBRE LOS LÍMITES DEL

CONTROL JUDICIAL DEL DEBIDO

PROCESO EN LOS

PROCEDIMIENTOS

DESARROLLADOS

ANTE LAS

COMISIONES

INVESTIGADORAS

DEL CONGRESO DE

LA REPÚBLICA

GENERAL

CONCERNS ON

THE JUDICIAL

SUPERVISION

LIMITS OFTHE

DUE PROCESS IN

THE PROCEDURES

BEFORETHE

INOUIRY

COMMISSIONS IN

THE CONGRESS 
Al fallar el caso, el juez constitucional de primera instancia del Poder Judicial concluyó que no existe afectación al procedimiento preestablecido, por cuanto el Reglamento del Congreso no establece un procedimiento especial que haya sido vulnerado. Asimismo, sostuvo que el denominado «Reglamento de la Comisión», dado que desagrega los contenidos del artículo 88 que regula el procedimiento de investigación, debe ser entendido como una suerte de guía metodológica para el mejor desarrollo del trabajo de la Comisión, pero no puede ser considerado una norma legal.

Respecto al derecho a comunicación previa y detallada de los hechos por los que se le investiga, concluyó el juez constitucional que el hecho de que García sea investigado y no acusado no enerva la obligación de comunicarle los hechos por los cuáles se le investiga, ya que investigarlo por el mero hecho de haber sido presidente de la República, supondría un acto que busca perjudicar al adversario político. Por ello, al analizar la citación dada por la Comisión al expresidente, concluyó que esta no contiene el detalle claro y preciso de los hechos por los cuáles se le investiga, por ello, este extremo de la demanda fue acogido.

Correlato de lo anterior es que se considere afectado el derecho a la defensa, por cuanto, al no conocer el investigado los hechos materia de investigación, no puede preparar de manera adecuada su defensa. Este extremo de la demanda también fue acogido. Finalmente, se analizaron diversas declaraciones dadas a la prensa por el presidente de la Comisión, lo que llevó a concluir que no se advierta una afectación al juez parlamentario imparcial, por cuanto el «[...] señor Tejada viene efectuando declaraciones a la prensa sobre un procedimiento no concluido [...] no hay elemento probatorio directo que acredite que el señor Tejada tenga una opinión formada sobre lo que se investiga $[\ldots] »$.

Por lo expuesto, la demanda es declarada fundada en parte. Cabe precisar que si bien el expresidente García, en su petitorio, solicitó se le excluya de la investigación, en la sentencia se decidió rechazar esta pretensión, pues se consideró que el procedimiento de investigación aún podía ajustarse a los cánones del debido proceso establecidos en su sentencia. Cabe añadir que, la sentencia fue apelada por el procurador del Congreso de la República, habiendo sido confirmada por la instancia superior $^{10}$. 


\section{III.2. Caso Alejandro Toledo Manrique}

El Parlamento peruano ha abierto investigación contra el expresidente Alejandro Toledo Manrique por presunto desbalance patrimonial. Los hechos, de notoria difusión, se pueden resumir en lo siguiente: se ha descubierto una empresa (ECOTEVA) constituida en Costa Rica cuya accionista principal resulta ser la octogenaria suegra del expresidente. Dicha situación no tendría nada de sospechoso, si no fuera por el hecho de que dicha empresa ha adquirido una serie de inmuebles por un valor que supera los tres millones de dólares (un inmueble en el distrito residencial de La Molina y una oficina en el distrito financiero de San Isidro). Toledo, siguiendo la estrategia de García, ha cuestionado a la Comisión Investigadora ante el Poder Judicial, mediante un hábeas corpus interpuesto por terceras personas en su favor.

En su demanda, que ha sido rechazada por el Poder Judicial ${ }^{11}$, Toledo argumentaba lo siguiente: se le afectó la garantía de la debida motivación (al haberse empleado para justificar la creación de la Comisión el concepto indeterminado de «interés público»), vulneración del derecho a la defensa y la asistencia letrada, derecho a no ser compelido a declarar o reconocer culpabilidad contra sí mismo, al respeto del procedimiento preestablecido, comunicación previa y detallada de los cargos en sede parlamentaria, vulneración del derecho a ser oído, derecho a la concesión del tiempo adecuado para preparar su defensa, derecho a intervenir en igualdad de condiciones en la actividad probatoria, violación de la garantía de sometimiento a una investigación parlamentaria independiente e imparcial, vulneración del derecho a la defensa, y a la debida motivación en el levantamiento del secreto bancario y amenaza potencial a su libertad individual.

En la sentencia, el juez constitucional entiende que lo que en el fondo cuestiona Toledo son amenazas a los derechos que invoca en la demanda, por ello, exige que tales amenazas sean ciertas y de inminente realización. Sin embargo, en una evidente falta de motivación o argumentación, se concluye que tales amenazas no son tal, pues, por un lado, se advierte que Toledo asistió a la Comisión Investigadora acompañado de su abogado defensor y, por otro lado, la Comisión que investiga a Toledo aún no evacúa su informe, por lo que todo lo alegado por el expresidente no son más que meras apreciaciones o afirmaciones carentes de sustento.

CONSIDERACIONES GENERALES SOBRE LOS LÍMITES DEL

CONTROL JUDICIAL DEL DEBIDO

PROCESO EN LOS

PROCEDIMIENTOS

DESARROLLADOS

ANTE LAS

COMISIONES

INVESTIGADORAS

DEL CONGRESO DE

LA REPÚBLICA

GENERAL

CONCERNS ON

THE JUDICIAL

SUPERVISION

LIMITS OFTHE

DUE PROCESS IN

THE PROCEDURES

BEFORETHE

INOUIRY

COMMISSIONS IN

THE CONGRESS 


\section{UN CASO PARADIGMÁTICO: CONTROL JUDICIAL DE LA SANCIÓN IMPUESTA AL CONGRESISTA JAVIER DIEZ CANSECO ${ }^{12}$}

En el contexto del presente trabajo resulta de especial interés revisar el caso del correcto congresista Javier Diez Canseco, hoy fallecido. Como se recordará, el congresista Diez Canseco fue sometido a una investigación dentro de la Comisión de Ética del Parlamento y luego sometido su informe acusatorio en mayoría ante el Pleno del Congreso, que lo suspendió por noventa días en el ejercicio de su función parlamentaria. En la investigación se concluyó que el congresista había cometido una falta ética pues había presentado un proyecto de ley que, de aprobarse, hubiera favorecido alguno de sus familiares directos.

El congresista cuestionó la sanción parlamentaria ante el Poder Judicial. Este, concluyó que en dicho procedimiento se habían vulnerado algunos derechos vinculados al debido proceso del congresista. En dicho sentido, en la sentencia ${ }^{13}$ se señaló que se acusaba al congresista de no haber informado sobre un posible conflicto de intereses al momento de presentar un proyecto de ley, cuando el Código de Ética Parlamentaria exigía que dicho deber de transparencia se diera al interior de una investigación o en el debate parlamentario en el Pleno para la aprobación de una ley. Por ello, no se podía sancionar al congresista por un hecho que no se subsumía en la norma que establecía el deber de transparencia en una etapa distinta a la que era objeto de acusación.

Asimismo, se indica que el uso del término «conflicto de intereses» en el informe acusatorio constituye el uso de un concepto jurídico indeterminado, por lo que en aplicación del principio de taxatividad, el mismo no podía ser utilizado como parámetro para enjuiciar y sancionar el comportamiento del congresista. Ello, por cuanto en el Código de Ética no se había establecido como falta ética la presentación de un proyecto de ley en el que el proponente tenga un interés directo, ya sea económico, familiar, social, etcétera. Finalmente, se concluyó que se vulneró el derecho a la comunicación previa y detallada de los hechos materia de denuncia, puesto que, en el debate ante el Pleno, el congresista que formuló la acusación contra Javier Diez Canseco introdujo un hecho que no había sido objeto de la investigación previa ante la Comisión de Ética.

12 LANDA, César. «La actuación de las sentencias impugnadas: El caso del congresista Diez-Canseco». Revista Jurídica, I, 3 (2013), pp. 1-10.

13 Sentencia de fecha 04 de abril de 2013, expediente 461-2013, emitida por el Quinto Juzgado Especializado en lo Constitucional de la Corte Superior de Justicia de Lima. 


\section{LÍMITES AL CONTROL JUDICIAL DEL RESPETO \\ AL DEBIDO PROCESO EN LOS PROCEDIMIENTOS ANTE LAS COMISIONES INVESTIGADORAS DEL PARLAMENTO}

A partir de los casos reseñados es posible formular algunas consideraciones de importancia:

a. Sobre el juicio político. En el caso de la sentencia de la Corte IDH de los magistrados del TC contra el Perú, el control del debido proceso parlamentario se efectúo sobre la base de un juicio político concluido, mediante resoluciones legislativas del Pleno de Congreso, que terminó en la destitución de los magistrados Revoredo, Aguirre Roca y Rey Terry, es decir, en la aplicación de una sanción que varió la situación jurídica de los afectados.

b. Sobre el antejuicio político. En el caso Tineo Cabrera, resuelto por el TC, se cuestionaba un procedimiento de antejuicio político, en el que, por acuerdo del Pleno del Congreso, se dispuso la denuncia ante el Ministerio Público; en mérito a que existía una calificación de los hechos, en sede parlamentaria, desde la perspectiva penal ${ }^{14}$; ello a fin de posibilitar luego, con el levantamiento de la inmunidad, el juzgamiento por el Poder Judicial del funcionario público sometido a control político.

c. Sobre la investigación parlamentaria. En el caso de Alan García no estamos frente a una decisión del Pleno del Congreso, sino frente a la labor de una Comisión de Investigación en sede parlamentaria, no penal. Adicionalmente, la citada Comisión ni siquiera tenía alguna conclusión adoptada sobre si el expresidente había tenido algún tipo de participación en los hechos investigados. Por ende, cabría sostener que no había certeza siquiera sobre los hechos que pudieran resultarle imputables.

d. Sobre la fiscalización parlamentaria. En el caso de la investigación parlamentaria realizada por una Comisión de Fiscalización al expresidente Toledo, si bien el juez no ingresó al fondo de la controversia, sí cabría llamar la atención sobre la forma en la que se planteó la pretensión, ya que esta determinó finalmente el rechazo de la demanda. En esta se alegó la mayor cantidad posible de derechos vinculados al debido proceso. Por exigencias procesales, dado que se trataba de un hábeas corpus conexo, en el análisis de procedencia de la demanda se tuvo en cuenta que todos los derechos invocados estaban vinculados con la libertad individual. Realizado el análisis, se concluyó que la libertad

CONSIDERACIONES GENERALES SOBRE LOS LÍMITES DEL

CONTROL JUDICIAL DEL DEBIDO

PROCESO EN LOS PROCEDIMIENTOS DESARROLLADOS

ANTE LAS

COMISIONES

INVESTIGADORAS

DEL CONGRESO DE LA REPÚBLICA

GENERAL

CONCERNS ON

THE JUDICIAL

SUPERVISION

LIMITS OFTHE

DUE PROCESS IN

THE PROCEDURES

BEFORETHE

INOUIRY

COMMISSIONS IN

THE CONGRESS 
individual no resultaba amenazada, por lo que los derechos conexos invocados tampoco. Por ello, el hábeas corpus fue rechazado.

e. Sobre la sanción parlamentaria. En el caso Diez Canseco, la justicia constitucional en el ámbito del Poder Judicial realizó el análisis de la aplicación de una sanción definitiva del Pleno del Congreso, que fue aplicada y hecha efectiva en la persona del congresista Javier Diez Canseco en el marco de una denuncia de la Comisión de Ética del Congreso.

De la síntesis efectuada podemos concluir que en los casos de los magistrados del TC destituidos, así como de Tineo Cabrera y del congresista Diez Canseco se cuestionaba un acto firme y definitivo tomado en sede parlamentaria, en donde incluso el Pleno del Congreso había adoptado decisiones que incidían negativamente en la situación jurídica de los afectados: destitución, procesamiento en sede judicial penal ordinaria, o la sanción de suspensión como parlamentario. Cualesquiera de esos casos, dado que el agravio se había producido, justificaba que el control judicial sobre el respeto del debido proceso en dicha sede sea más estricto o intenso ${ }^{15}$. Más aún, cuando temporalmente el control constitucional del debido proceso se realizó luego de que se adoptaran las decisiones finales y firmes reseñadas.

En cambio, en los otros casos, particularmente en el del expresidente García, a pesar de que aún ni siquiera existían conclusiones preliminares de parte de la respectiva Comisión, en sede judicial se optó por un control constitucional estricto del debido proceso, temporalmente anterior a la adopción del informe preliminar o final que contiene la decisión parlamentaria sobre las investigaciones realizadas. Nosotros consideramos que ello no debe ser así, pues el Parlamento como órgano que investiga asuntos en los que los gobernantes o exgobernantes ( $y$ en general cualquier otro alto funcionario público) puedan verse involucrados, no debería ver entorpecido el ejercicio de sus facultades investigadoras, cuando estas aún no han establecido con claridad y precisión los hechos imputables. Más aún en el caso de los exgobernantes, pues el volumen de documentación que en dichos casos debe revisarse sobrepasa la capacidad operativa de sus propios miembros.

Por ello, consideramos que el control constitucional del debido proceso parlamentario de la actuación de las comisiones investigadoras debería flexibilizarse y transitar por un canon que atienda a las particulares circunstancias que rodean cada caso concreto. No debe olvidarse que

15 Respecto del debido proceso en los juicios políticos desarrollados en el Perú, ver CAIRO RoLdAN, Omar. "Alcances y límites del debido proceso en la experiencia del juicio político (2001-2005)». En Congreso de la República. Primer y segundo congreso de derecho parlamentario. Lima: Congreso de la República. Oficialía Mayor, 2012, pp. 196-197. 
existen diferencias sustantivas entre el antejuicio y el juicio político, y las actuaciones desarrolladas por las comisiones investigadoras $\mathrm{o}$ de fiscalización. Así, mientras que los primeros son procedimientos parlamentarios materialmente jurisdiccionales, pues inciden en la esfera jurídica de los funcionarios encausados, en el segundo no necesariamente es así, en tanto la finalidad de la investigación parlamentaria reside en el esclarecimiento de hechos de notoria relevancia pública. Esto, evidentemente sin perjuicio de que si se descubren indicios de responsabilidad política o responsabilidad penal, se concluya con que la investigación se derive ante las instancias correspondientes y se instauren los procedimientos de antejuicio o juicio político que correspondan ${ }^{16}$.

Sin perjuicio de ello, debería existir un control estricto sobre las reglas de procedimiento establecidas en el artículo 88 del Reglamento del Congreso $^{17}$. Esta norma establece, entre otras cosas, el procedimiento de conformación de la Comisión, los límites derivados de la protección del derecho a la intimidad, la reserva de las sesiones, la obligaciones de los ciudadanos y autoridades de brindar todo tipo de información vinculada al tema investigado a solicitud de la Comisión, la posibilidad de levantar el secreto bancario y la reserva tributaria, el procedimiento de aprobación del informe, el contenido del informe, su debate en el Pleno, entre otros temas de procedimiento.

\section{CANON DE CONTROL CONSTITUCIONAL DEL DEBIDO PROCESO}

\section{VI.1. Debido proceso: entre reglas y principios}

En el control judicial de los casos de investigación parlamentaria, losjueces operan con normas constitucionales y del Reglamento del Congreso que contienen distintas disposiciones y normas sobre la naturaleza jurídica del debido proceso. Así, en la dogmática constitucional contemporánea,

16 Sobre las diferencias entre el antejuicio y el juicio político, ver GARCíA CHÁvARRI, Abraham. Acusación constitucional y debido proceso. Estudio del modelo peruano de determinación de responsabilidad de los altos funcionarios por parte del Congreso de la República. Lima: Jurista Editores, 2008, pp. 47, 107 y 115. También las voces "antejuicio" y «juicio político» en AUTORES VARIOS. Diccionario de derecho constitucional contemporáneo. Lima: Gaceta Jurídica, 2012, pp. 25-27 y 278-279.

17 Podría objetarse el hecho de que el artículo 88 del Reglamento del Congreso no contiene solo normas de procedimiento, sino también normas de carácter sustantivo, esto es reconocimiento de derechos subjetivos. Ello, en tanto y en cuanto, en su desarrollo se aludiría a derechos fundamentales tales como la intimidad personal y familiar, el honor, el secreto bancario, la reserva tributaria y la libertad individual. Sin embargo, no debe olvidarse que los derechos citados son derechos reconocidos en la Constitución: honor e intimidad (artículo 2.7), secreto bancario y reserva tributaria (artículo 2.5), libertad individual (artículo 2.24), y lo que hace el Reglamento del Congreso es regular las limitaciones que pueden ser realizadas por las comisiones investigadoras, en tanto las limitaciones y el ejercicio de los derechos se realiza vía intermediación legislativa. Si bien tal regulación podría calificarse como sustantiva, no es menos cierto que lo que en realidad se concreta son las formas o procedimientos mediante los cuales las comisiones investigadoras pueden limitar válidamente los derechos antes enumerados. Sobre el concurso del legislador en la configuración de los límites de los derechos, ver PÉREZ TREMPS, Pablo. «La interpretación de los derechos fundamentales». En Eduardo FerRer MAC-Gregor. Interpretación constitucional. Tomo II. México: Porrúa, 2005, p. 910.

CONSIDERACIONES GENERALES SOBRE LOS LÍMITES DEL

CONTROL JUDICIAL DEL DEBIDO

PROCESO EN LOS

PROCEDIMIENTOS DESARROLLADOS

ANTE LAS

COMISIONES

INVESTIGADORAS

DEL CONGRESO DE

LA REPÚBLICA

GENERAL

CONCERNS ON

THE JUDICIAL

SUPERVISION

LIMITS OFTHE

DUE PROCESS IN

THE PROCEDURES

BEFORETHE

INQUIRY

COMMISSIONS IN

THE CONGRESS 
a raíz de los debate sobre los límites y posibilidades del positivismo jurídico entre H.L.A. Hart ${ }^{18}$ y Ronald Dworkin, se discute sobre el mejor entendimiento de los derechos fundamentales, como el debido proceso, entendido en la forma de principios o de reglas.

Como se sabe, el entendimiento estándar en materia de derechos fundamentales, siguiendo a Alexy ${ }^{19}$, es que los derechos fundamentales deben ser comprendidos como principios, es decir, como mandatos de optimización, en buena cuenta, mandatos de deber ser que ordenan que los derechos se cumplan en la mayor medida posible, teniendo en cuenta para ello las posibilidades fácticas y jurídicas. Esto último es así en tanto semánticamente no se ha formulado, al menos no de modo exhaustivo, las condiciones de aplicación del principio (supuesto de hecho) ni las consecuencias jurídicas de dicha aplicación. Sin embargo, el entendimiento de Alexy de los derechos como principios no objeta la existencia de derechos que asumen la forma de reglas ${ }^{20}$.

Un caso paradigmático de esta situación lo constituye el derecho al debido proceso. Como bien sabemos, el derecho al debido proceso es considerado un derecho principio, es decir, un instituto que incorpora una pluralidad de derechos y que la lesión de cada uno de sus contenidos equivale a su propia lesión ${ }^{21}$. En dicho entendimiento, por su formulación semántica en la Constitución de 1993, se podría considerar que algunos de los contenidos del derecho a un debido proceso asumen la forma de principios (mandatos de optimización), en tanto que otros asumen la forma de reglas (se cumplen todo o nada). La distinción no es meramente conceptual, sino que acarrea como consecuencia práctica una obligación judicial o un derecho del justiciable a exigir una forma o método de aplicación del derecho involucrado en el caso. De esta manera, para los principios corresponderá aplicar el principio de proporcionalidad ${ }^{22}$, en tanto que para las reglas la subsunción.

18 HART, H.L. A. El concepto de derecho. Buenos Aires: Abeledo Perrot, 1962; DwORKIN, Ronald. Los derechos en serio. Barcelona: Ariel, 1984.

19 ALEXY, Robert. Teoría de los derechos fundamentales. Madrid: Centro de Estudios Constitucionales, 1991, p. 67.

20 ALEXY, Robert. «Derechos, razonamiento jurídico y discurso racional». Isonomía. Revista de Teoría y Filosofía del Derecho, 1 (1994), pp. 40-41. Ciertamente la distinción entre reglas y principios no ha estado exenta de críticas, al respecto pueden verse AARNIO, Aulis. «Reglas y principios en el razonamiento jurídico" (http://ruc.udc.es/bitstream/2183/2070/1/AD-4-35.pdf); CIANCIARDO, Juan. «Reglas y principios: una aproximación desde los criterios de distinción». Boletín Mexicano de Derecho Comparado, XXXVI, 108 (2003), pp. 903ss.

21 LANDA ARROYo, César. El derecho al debido proceso en la jurisprudencia. Corte Suprema de Justicia de la República del Perú, Tribunal Constitucional del Perú, Corte Interamericana de Derechos Humanos. Lima: Academia de la Magistratura, 2012, pp. 15, 60 y 109. En dicho sentido, puede revisarse la sentencia del expediente 4287-2012-AA, fundamento 4.3.

22 El principio de proporcionalidad es una herramienta metodológica para la aplicación de los derechos fundamentales mediante la cual se determina la legitimidad de las medidas que intervienen derechos. Está compuesto por exámenes: test de idoneidad, test de necesidad y test de ponderación o proporcionalidad en sentido estricto. Mientras que la subsunción supone verificar la adecuación de los hechos en el supuesto hipotético previsto en la norma, si esto se verificaba, correspondía la aplicación de la consecuencia prevista en la misma norma. Al respecto, ver BERNAL PULIDO, Carlos. «La ponderación como método para interpretar los derechos fundamentales». En Enrique CÁCERES 
En el sentido anotado, cuando se revisan las garantías de la función jurisdiccional establecidas en el artículo 139 de la Constitución peruana, se advierte la enunciación de una serie de derechos que pueden adoptar la forma de principios, en tanto que otros la forma de reglas. En dicho sentido, en el artículo 139.3 se reconoce como derecho «la observancia del debido proceso y la tutela jurisdiccional», sin embargo, no se aprecia, a partir de dicha redacción, qué es o en qué supuestos se «observa» o no el debido proceso o la tutela jurisdiccional, es el juez quien debe delimitar esto en función de la naturaleza del proceso en curso. Asimismo, no se indica la consecuencia que acarrea su no observancia. Lo mismo sucede con el principio de publicidad de los procesos, según lo establecido en el artículo 139.4, o con el derecho a la pluralidad de instancias reconocido en el artículo 139.6, entre otros.

Dada la amplitud de su reconocimiento semántico, los mismos bien podrían calificar como principios, lo que conlleva que su aplicación en todo proceso y, en consecuencia, su control judicial pueda darse mediante el principio de razonabilidad y proporcionalidad. Es decir, se diferencia la exigencia del debido proceso como principio frente a procesos judiciales, procedimientos administrativos o procedimientos parlamentarios, aunque no todos en la misma intensidad, dada la naturaleza jurídica de las cosas. De esta manera, mediante el anotado principio podrían analizarse las opciones legislativas adoptadas en relación, por ejemplo, con el número de recursos previstos en la legislación procesal, que precisamente permiten el ejercicio del derecho a la pluralidad de instancias. Así, podría considerarse no idóneo, necesario y proporcional un proceso o procedimiento administrativo de una sola instancia, aunque podría sí serlo frente a un juicio político en tanto proceso parlamentario, dado que llevaría una sanción — suspensión, destitución o inhabilitación del cargo público- . También podría ser objeto de análisis la decisión judicial de excluir del conocimiento del público el trámite de casos que bien podrían mantenerse en reserva como el proceso parlamentario del antejuicio político de altos funcionarios por delitos de corrupción o lavado de activos.

En uno y otro caso hipotético se ponderan los derechos anotados, como por ejemplo la eficacia de la tutela judicial, pues un proceso con muchas instancias podría hacer ilusoria la protección judicial de los derechos; o el principio de publicidad con el derecho a la intimidad de los procesados o la seguridad nacional, dependiendo de los temas que sean objeto de procesamiento (por ejemplo, en materia del narcotráfico).

De otro lado, también se aprecia que otros derechos del artículo 139 están formulados de manera más precisa, como prohibiciones:

CONSIDERACIONES GENERALES SOBRE LOS LÍMITES DEL

CONTROL JUDICIAL DEL DEBIDO

PROCESO EN LOS

PROCEDIMIENTOS

DESARROLLADOS

ANTE LAS

COMISIONES

INVESTIGADORAS

DEL CONGRESO DE

LA REPÚBLICA

GENERAL

CONCERNS ON

THE JUDICIAL

SUPERVISION

LIMITS OFTHE

DUE PROCESS IN

THE PROCEDURES

BEFORETHE

INOUIRY

COMMISSIONS IN

THE CONGRESS 
«ninguna autoridad puede avocarse a causas pendientes ante el órgano jurisdiccional», «ninguna autoridad puede dejar sin efecto resoluciones que han pasado en autoridad de cosa juzgada», «ninguna autoridad puede cortar procedimientos en trámite», «ninguna autoridad puede modificar sentencias, ni retardar su ejecución» (todos contenidos en el artículo 139.2), «ninguna persona pude ser desviada de la jurisdicción predeterminada por la ley», «ninguna persona puede ser sometida a procedimiento distinto de los previamente establecidos» (contenidos en el artículo 139.3), «no ser condenado en ausencia» (artículo 139.12), «la prohibición de revivir procesos fenecidos con resolución ejecutoriada» (artículo 139.13), «no ser privado del derecho de defensa en ningún estado del proceso» (artículo 139.14); o como mandato: «toda persona debe ser informada, inmediatamente y por escrito, de las razones de su detención» (artículo 139.15), entre otras. Se trata de prohibiciones y mandatos en principio propios de un proceso judicial.

No cabe duda de que los derechos enumerados en el párrafo precedente tienen un supuesto de hecho más concreto o preciso, lo que conllevaría a calificarlos como normas reglas y, por ende, su aplicación en un caso concreto debería darse vía subsunción del hecho en la norma. Por ello, si en un caso los hechos alegados guardan relación con el supuesto enunciado, se aplica la consecuencia, consistente en la nulidad o invalidez de los actos lesivos del derecho demandado. En todo caso, la lesión a alguno de los derechos enumerados acarrea su propia lesión y la del debido proceso; pero ello configura una obligación del juez constitucional encargado del control judicial de discernir la naturaleza del debido proceso ante los diferentes tipos de procedimientos parlamentarios.

\section{VI.2. Contenido del debido proceso exigible en los procedimientos de investigación parlamentaria}

Según el caso objeto de análisis, la exigencia del juez constitucional del respeto del debido proceso en las comisiones de investigación parlamentaria pasa por equiparar a las funciones de estas con las labores de una investigación de las autoridades judiciales, asumiendo que sus decisiones tienen consecuencias en la esfera de los derechos de los involucrados en las investigaciones. En buena cuenta, se trata de una suerte de homologación de las facultades parlamentarias con las judiciales. Como sabemos, en el derecho comparado se puede encontrar hasta tres tipos de posturas en torno a esta cuestión: homologación total (Italia, Portugal), una homologación relativa (Alemania) y una no equiparación por silencio (España) ${ }^{23}$. Sin embargo, a partir de la

23 LEÓN VÁSQUEZ, Jorge. Los poderes y límites de las comisiones parlamentarias de investigación en el derecho constitucional peruano. Tesis para obtener el título profesional de abogado. Lima: 
distinción entre reglas y principios y desde una perspectiva normativa, de deber ser, consideramos que el debido proceso en sede de investigación parlamentaria impone a la propia comisión investigadora el respeto estricto de las reglas procedimentales establecidas en el artículo 88 del Reglamento del Congreso de la República.

Estas reglas, como se sabe, están referidas a la forma de constitución de la comisión investigadora, al levantamiento de la reserva de las sesiones, al contenido del informe, a la presentación del mismo dentro del plazo otorgado, al procedimiento de aprobación ante el Pleno, a los límites de la divulgación de informaciones vinculadas a la intimidad, secreto bancario y reserva tributaria de los investigados, entre otras. En segundo lugar, consideramos que, desde la perspectiva de los investigados, resulta exigible a la comisión investigadora el respeto de una serie de principios derechos que deberían incorporarse, mutatis mutandi, sin que ello signifique en modo alguno judicializar el procedimiento parlamentario de investigación. Al contrario, se trata de realizar el principio de control y balance de poderes, que es la versión contemporánea del clásico principio de la separación de los poderes. En ese entendido, entre los principios-derechos exigibles en los procedimientos de investigación parlamentaria se pueden señalar los siguientes ${ }^{24}$.

a. El principio de inmediación, que significa que quienes van a investigar estén en contacto directo con los funcionarios o personas investigadas. Esto es importante puesto que es frecuente, en la práctica parlamentaria, que todos los miembros de la comisión investigadora no estén presentes mientras se desarrollan las actuaciones de investigación.

b. Principio de imparcialidad, ya que si consideramos que la actuación parlamentaria está regida por criterios de oportunidad y conveniencia política, la imparcialidad viene a constituir un mecanismo de ponderación, morigeración y de racionalidad de las decisiones que vaya adoptar la Comisión Investigadora, con la finalidad de no caer en la arbitrariedad. Por ello, en el Reglamento del Congreso se establece que quienes solicitan la conformación de una comisión investigadora no pueden formar parte de ella.

c. Respeto al derecho de defensa, a fin de que los investigados, de considerarlo pertinente, puedan conocer los elementos indiciarios de la investigación preliminar, ofrecer los medios probatorios que consideren convenientes, tener acceso a la documentación (siempre que no suponga afectar el derecho a

CONSIDERACIONES GENERALES SOBRE LOS LÍMITES DEL CONTROL JUDICIAL DEL DEBIDO PROCESO EN LOS PROCEDIMIENTOS DESARROLLADOS

ANTE LAS

COMISIONES

INVESTIGADORAS DEL CONGRESO DE LA REPÚBLICA

GENERAL

CONCERNS ON

THE JUDICIAL SUPERVISION LIMITS OFTHE DUE PROCESS IN THE PROCEDURES BEFORETHE

INOUIRY

COMMISSIONS IN THE CONGRESS 
la intimidad personal y familiar, la reserva tributaria o el secreto bancario de otros investigados o testigos), ser asistido por un abogado de su elección y, en su caso, dependiendo del avance de las indagaciones, conocer las causas por las cuáles se le investiga.

d. Principio de oralidad, que impone la incorporación y actuación oral de los medios de prueba en la investigación.

e. Principio de publicidad, según el cual se garantiza el control, por parte de la ciudadanía y de la sociedad en general, de las decisiones que se adopten. Ello implica, a su vez, legitimar dichos actos desde que estos son conocidos enteramente por la opinión pública.

Ahora bien, habiendo establecido qué principios y reglas del debido proceso resultan exigibles ante las comisiones de investigación, conviene preguntarnos cuál debe ser el canon del control judicial y su intensidad sobre el respeto a los derechos fundamentales.

\section{VI.3. Intensidad del control del debido proceso en sede parlamentaria de investigación: del control débil al control estricto}

El control judicial de una investigación parlamentaria que realiza una Comisión Investigadora suponer per se una intervención en las facultades parlamentarias, poniendo en cuestión el principio de la separación de poderes, establecido en el artículo 43 in fine de la Constitución. Sin embargo, puesto que dicho clásico principio es concebido en las democracias contemporáneas como el control y balance de poderes, debe enfatizarse que el control judicial de la actuación de una Comisión Investigadora puede revestir diversos grados de intensidad, según la gravedad de la violación y la ocasión en que la misma pueda presentarse.

Así, siguiendo las tesis del TC con relación al alcance y los límites del control de la justicia constitucional sobre las resoluciones judiciales ordinarias ${ }^{25}$, mutatis mutandi, se puede señalar que se requiere establecer un canon del control judicial para la actuación parlamentaria en las comisiones investigadoras, distinto del juicio político, del ante juicio, de las tareas de las comisiones de comisión de ética, dado que solo estas últimas son las que tienen facultades para afectar los derechos políticos de los altos funcionarios públicos denunciados, previstos en el artículo 99 de la Constitución. Por eso, la intensidad del control judicial de los actos o resoluciones parlamentarias depende de la interpretación que se haga de la configuración constitucional de los mencionados procesos 
parlamentarios. Sin embargo, se parte de un criterio objetivo, según el cual los altos funcionarios, que han pedido el voto ciudadano para su elección y/o manejan fondos públicos, deben estar sometidos a un mayor grado de control político y, en consecuencia, el control judicial de dicha actuación debe ser subsidiario. Así, en términos generales, frente a una Comisión Investigadora se puede establecer dos tipos de actuación judicial, mediante una de las siguientes medidas:

a. Interpretación estricta del amparo, en la cual los jueces constitucionales examinen la constitucionalidad del informe final de la Comisión Investigadora, dando mérito constitucional suficiente a los actos parlamentarios realizados, en cumplimiento de su función política de investigar asuntos de interés público. En esta perspectiva, el juez constitucional asume lo actuado por la Comisión de Investigación iure et de iure. Luego de ello se pasa a realizar un examen de la motivación y relevancia constitucional del Informe preliminar o final de la Comisión en función del derecho fundamental invocado.

b. Interpretación flexible del amparo, que se produciría cuando el juez constitucional adquiere plena jurisdicción sobre el fondo y la forma del proceso de investigación parlamentario, realizando un examen constitucional de la motivación del Informe de la Comisión y de la relevancia de lo actuado en el proceso parlamentario. En este caso, el juez tendría la posibilidad de revisar todo el proceso que va desde el examen del acto lesivo, la validez o no de las normas legales, hasta el valor probatorio de las pruebas; vale decir, revisando la actuación parlamentaria concreta que sea necesaria para determinar la constitucionalidad de la actuación cuestionada.

No obstante, la interpretación flexible del proceso de amparo requiere que el juez constitucional establezca un canon interpretativo para otorgar predictibilidad y seguridad jurídica a su intervención, bajo el cual realizará el control judicial de las resoluciones parlamentarias, sin que ello suponga convertir al Poder Judicial en un supra poder. Al contrario, esto tendría como finalidad reconocer que al juez constitucional le corresponde, en el proceso de amparo, resolver razonable y ponderadamente sobre el fondo y la forma de los procesos parlamentarios, de acuerdo con la naturaleza de sus fines.

Así, es distinto el objeto de una comisión de investigación parlamentaria, que no tiene como objetivo procesar y/o sancionar a un alto funcionario, para lo cual están previstos los procedimientos parlamentarios del juicio político, ante juicio, comisión de ética, fiscalización parlamentaria; donde es más proclive que se puedan violar los derechos fundamentales 
tutelados de los investigados, acusados o sancionados. No obstante, el juez constitucional debe analizar el proceso y el caso concreto bajo un parámetro o canon interpretativo ad-hoc. Dicho canon interpretativo le permitiría al juez constitucional realizar, legítimamente, el control constitucional de los actos parlamentarios y estaría compuesto, en primer lugar, por un examen de razonabilidad, en segundo lugar, por un examen de coherencia y, finalmente, por un examen de suficiencia ${ }^{26}$.

a. Examen de razonabilidad. Por el examen de razonabilidad, el juez constitucional debe evaluar si la revisión de todo el proceso parlamentario es relevante para determinar, por ejemplo, si el Informe Final de una Comisión de Investigación que se cuestiona vulnera el derecho fundamental que está siendo demandado.

b. Examen de coherencia. El examen de coherencia exige que el juez constitucional deba precisar si el acto lesivo del caso concreto se vincula directamente con el proceso o la decisión parlamentaria que se impugna; de lo contrario no estaría plenamente justificado el hecho de que el juez efectúe una revisión total del proceso parlamentario, si tal revisión no guarda relación alguna con el acto vulneratorio.

c. Examen de suficiencia. Mediante el examen de suficiencia, el juez constitucional debería determinar la intensidad del control constitucional que sea necesaria para llegar a precisar el límite de la revisión de los actos llevados a cabo en el proceso parlamentario, a fin de cautelar el derecho fundamental demandado.

Ahora bien, prima facie el punto de referencia para el control judicial vendría a ser el momento en el que una Comisión de Investigación presenta su informe final o preliminar, pues solo ahí se tiene certeza sobre las conclusiones, definitivas o preliminares, a las que la investigación arribó; salvo agravios que afecten los principios del debido proceso. Tomando esto en cuenta y en aras a respetar el principio democrático constitucional contemporáneo del control y balance de poderes ${ }^{27}$, solo podríamos hablar en principio de un control constitucional de dos niveles o intensidades que puede presentarse en dos momentos diferentes: antes y después de que se ha emitido el informe de la comisión. Entonces, se puede identificar un control judicial estricto ex ante y un control judicial débil ex post, tomando como referencia el momento en que se emite el informe de la comisión investigadora; en la medida en que, cualquier 
agravio a un derecho fundamental debe ser cierto y concreto o en caso de ser una amenaza debe ser de inminente afectación.

El control judicial debiera ser estricto en el respeto de la labor parlamentaria cuando se realice antes que las comisiones de investigación hayan concluido con sus investigaciones. Es decir, si aún no se emite el informe de la comisión donde no se produce una acusación o imputación sobre una eventual responsabilidad política o penal. En cuyo caso la autoridad judicial no debería entorpecer la labor investigadora con un escrutinio estricto de los componentes del debido proceso, sino preferir el desarrollo de la labor de investigación política del Congreso hasta su culminación, de conformidad con el artículo 97 de la Constitución. En cambio, el control judicial será flexible, una vez que la labor de la comisión haya concluido y se ha hecho público el informe que contiene sus conclusiones, en donde pueda establecerse presuntas responsabilidades a una autoridad que goza de la prerrogativa del ante juicio político; la misma que prevén los artículos 99 y 100 de la Constitución. En este caso, frente a una demanda de amparo, el escrutinio judicial deberá ser exigente con la actuación desplegada por la comisión durante sus investigaciones, a fin de asegurar que se haya respetado el debido proceso en sede parlamentaria, a través de los exámenes de razonabilidad, coherencia y suficiencia, antes señalados.

En el siguiente gráfico se resume lo expuesto:

\begin{tabular}{|c|c|}
\hline \multicolumn{2}{|c|}{$\begin{array}{c}\text { Momento en que } \\
\text { la Comisión Investigadora } \\
\text { emite su informe } \\
\text { (preliminar o final) }\end{array}$} \\
\hline $\begin{array}{c}\text { Control judicial estricto (ex ante del } \\
\text { informe preliminar o final) } \\
\text { Examen flexible de razonabilidad, } \\
\text { coherencia y suficiencia }\end{array}$ & $\begin{array}{c}\text { Control judicial flexible (ex post del } \\
\text { informe preliminar o final) } \\
\text { Examen estricto de razonabilidad, } \\
\text { coherencia y suficiencia }\end{array}$ \\
\hline
\end{tabular}

Con ello, se pretende salvaguardar el principio de equilibrio de poderes ${ }^{28}$, sin afectar innecesariamente la sede de investigación parlamentaria con innecesarias injerencias judiciales que puedan tener por objeto cerrar o entorpecer las investigaciones con la finalidad indirecta o directa de lograr algún grado de impunidad sobre los hechos investigados (de interés público) en materia de presunta corrupción gubernamental. Pero, también se busca que la función de control o fiscalización parlamentaria no afecte los derechos fundamentales de las minorías políticas. Para ello,

CONSIDERACIONES GENERALES SOBRE LOS LÍMITES DEL

CONTROL JUDICIAL DEL DEBIDO

PROCESO EN LOS PROCEDIMIENTOS DESARROLLADOS

ANTE LAS

COMISIONES

INVESTIGADORAS

DEL CONGRESO DE LA REPÚBLICA

GENERAL

CONCERNS ON

THE JUDICIAL

SUPERVISION

LIMITS OFTHE

DUE PROCESS IN

THE PROCEDURES

BEFORETHE

INQUIRY

COMMISSIONS IN THE CONGRESS 
el juez constitucional deberá ponderar si su intervención en relación con la materia objeto de la naturaleza de la investigación o acusación parlamentaria resulta razonable y proporcional. Tomemos como ejemplo el caso del expresidente García y la decisión adoptada por la autoridad judicial.

En dicho sentido, en el caso se entendió que se afectó el derecho a la comunicación previa y detallada de los hechos imputados al expresidente. Sin embargo, consideramos que dicho derecho debió ponderarse, en función a las circunstancias, con el derecho a la verdad (sentencia del expediente 2488-2002-HC, fundamentos 8 a 20) sobre asuntos de interés público. Este es el caso de una investigación sobre graves indicios de corrupción gubernamental en materia de gracias presidenciales a más de cuatrocientos reos por narcotráfico o la evasión de las normas públicas para la contratación de grandes obras de infraestructura social. Si bien el reconocimiento del derecho a la verdad ha estado vinculado con el esclarecimiento de las violaciones a derechos humanos, no es menos cierto que una dimensión del mismo, asociado al principio de transparencia de la gestión pública, también supone el esclarecimiento de presuntos actos de corrupción que podrían haber cometido autoridades públicas de alto nivel.

Entonces, en el caso en cuestión debió determinarse si la comunicación cursada al expresidente García para comparecer y rendir su declaración ante la comisión investigadora de su gestión, era una medida adecuada para llegar a la verdad o esclarecer su eventual participación en los hechos que eran objeto de investigación. Más aún, si el juez penal se encuentra investigando la denuncia por delitos de corrupción de funcionarios en la modalidad de cohecho pasivo propio y asociación ilícita para delinquir en el otorgamiento de las gracias presidenciales a reos por narcotráfico, más conocidas como los «narco-indultos» ${ }^{29}$.

En efecto, los «narco-indultos» han llevado al Poder Judicial a procesar al exministro de Justicia - Aurelio Pastor - quien rubricaba las resoluciones supremas de los indultos junto con el expresidente García. El proceso judicial también abarca a otros diez altos funcionarios, entre ellos a Facundo Chinguel — director de la Comisión de Indultos del Ministerio de Justicia - por el supuesto cobro a los favorecidos de los «narco-indultos». Evidentemente, dados los avances de las indagaciones al momento en que la comunicación fue cursada a García, dicha comunicación, en los términos en que fue redactada, constituía una medida adecuada para lograr llegar a la verdad política del caso. De otro lado, dado el estado de la investigación y que la propia Comisión de Investigación no tenía certeza acerca del tipo o grado de participación

29 GARCíA, Jaime y otros. Lucha contra el narcotráfico en el Perú: una estrategia para el gobierno 2011 2016. Lima: Pontificia Universidad Católica del Perú. Instituto de Estudios Internacionales, 2011. 
del expresidente García en los hechos investigados, no existía otra medida igual de idónea para lograr llegar a la verdad, pero que incida en menor intensidad en el derecho a la comunicación previa y detallada de las imputaciones.

Finalmente, debió ponderarse el derecho a la comunicación previa y detallada de las imputaciones no solo con el derecho a la verdad, sino también con el principio de transparencia que se desprende de los artículos 40 y 41 de la Constitución, con el principio de responsabilidad que se deriva del artículo 45 y que establece que «Quienes lo ejercen [el poder que emana del pueblo] lo hacen con las limitaciones y responsabilidades que la Constitución y las leyes establecen», y con el deber que tiene el Estado de combatir el narcotráfico que se deriva del artículo 8 de la Constitución, en tanto que, a la fecha en que la comunicación fue cursada, ya se habían acopiado hasta 400 gracias presidenciales otorgadas a sentenciados por narcotráfico.

Por ello, el control judicial no debió ser estricto, como si se tratara de un proceso concluido, sino que debió ser en todo caso un control flexible que debió encausarse hacia su verdadero ámbito de acción: las conclusiones de la investigación. Ya que antes de ello, lo actuado por la Comisión no incide de modo intenso en la esfera de derechos de los investigados de un asunto de interés público, de modo tal que haga irreconocible el derecho presuntamente afectado. Muy por el contrario, la intervención judicial, durante el desarrollo de las indagaciones de las comisiones investigadoras, entorpece su desarrollo y obstaculiza llegar a conclusiones sobre el objeto materia de investigación, que no es otra cosa que la lucha contra la corrupción endémica de muchas autoridades del Estado peruano ${ }^{30}$.

\section{REFLEXIONES FINALES: ¿JUDICIALIZACIÓN DE LA POLÍTICA O POLITIZACIÓN DE LA JUSTICIA?}

Encontrar los equilibrios necesarios para la sana convivencia de las instituciones dentro del Estado constitucional democrático es una tarea ciertamente ardua. Por ello es sobre la base del respeto a las competencias y funciones constitucionalmente establecidas que dichos equilibrios pueden encontrarse. En ese sentido, el control constitucional del respeto al debido proceso en las Comisiones de Investigación del Parlamento, desarrollado intensamente durante el último año, es un escenario que despierta tensiones al interior de las no siempre pacíficas relaciones entre el Poder Legislativo y la justicia constitucional. Por ello, no puede equipararse al debido proceso judicial con el debido proceso parlamentario. Al contrario, el reconocimiento del contenido de cada

CONSIDERACIONES GENERALES SOBRE LOS LÍMITES DEL

CONTROL JUDICIAL DEL DEBIDO

PROCESO EN LOS PROCEDIMIENTOS DESARROLLADOS

ANTE LAS

COMISIONES

INVESTIGADORAS

DEL CONGRESO DE LA REPÚBLICA

GENERAL

CONCERNS ON

THE JUDICIAL

SUPERVISION

LIMITS OFTHE

DUE PROCESS IN

THE PROCEDURES

BEFORETHE

INOUIRY

COMMISSIONS IN THE CONGRESS 
derecho en su propio ámbito abre las vías para un sano entendimiento entre la potestad del Parlamento de investigar a través de Comisiones Investigadoras y de la justicia constitucional de tutelar los derechos fundamentales.

Por lo tanto, debe postularse un control ex ante del debido proceso en sede parlamentaria que tenga una intensidad débil, de modo tal que no se obstaculice la labor fiscalizadora de la representación nacional. De otro lado, una vez que las competencias congresales hayan culminado en el Informe de la Comisión Investigadora, resulta exigible un control judicial estricto o intenso del respeto al debido proceso en dicho procedimiento parlamentario, esto es un control ex post.

Finalmente, creemos que con este entendimiento se puede evitar una innecesaria judicialización de la política, en donde, como diría Carl Schmitt, la política no tiene nada que ganar y la justicia, todo que perder. 